\title{
Pyrolysis gases released during the thermal degradation of insulation materials based on straw fibers
}

\author{
Khaled Chetehouna - Naima Belayachi • \\ Laurent Lemée · Dashnor Hoxha • Borja Rengel
}

Received: 28 October 2014/Accepted: 15 February 2015/Published online: 16 July 2015

(C) Akadémiai Kiadó, Budapest, Hungary 2015

\begin{abstract}
Interest in recovering and valorizing agricultural biomass residues has increased in recent years in response to emerging economic opportunities and the potential for more sustainable use of renewable and easy available resources. The present research has been carried out to understand and analyze the gaseous emissions during thermal degradation of the new straw fiber concrete developed for insulation application. Two straw fibers (wheat and barley) and two binders (plaster and lime) have been collected and mixed with different $S / B$ ratios to conceive thermal insulation composites. Gaseous emissions are required as a crucial investigation firstly to evaluate the environmental and human pollution and secondly to predict the ignition of these new materials. Py-GC/MS analyses have been carried out for basic and composite materials at $300{ }^{\circ} \mathrm{C}$. The thermal degradation of straws essentially released cellulose, lignin moieties and trimethyl pentadecanone. Composite materials, produced 27 compounds when submitted to a temperature of $300{ }^{\circ} \mathrm{C}$. The straw
\end{abstract}

K. Chetehouna ( $\square)$

INSA Centre Val de Loire, University of Orléans, PRISME EA

4229, F-18022 Bourges, France

e-mail: khaled.chetehouna@insa-cvl.fr

N. Belayachi · D. Hoxha

University of Orléans, INSA Centre Val de Loire, PRISME, EA

4229, F-45072 Orléans, France

L. Lemée

University of Poitiers, CNRS UMR 7285 (IC2MP),

F-86073 Poitiers, France

B. Rengel

ASHES Fire Consulting S.A., C/Playa de las Américas,

28290 Las Matas, Madrid, Spain composite materials gaseous emissions appear to be influenced by binder nature and $S / B$ ratio.

Keywords Composite materials - Organic compounds · Straw/binder ratio $\cdot$ Py-GC/MS $\cdot$ Gaseous emissions

\section{Introduction}

Nowadays, the green building materials have become a major issue in order to improve and maximize energy performance and minimize energy consumption. Natural fibers reinforced composites are good candidates to substitute conventional synthetic fibers reinforced polymers for some applications such as automotive and aerospace [1]. These composites are cost-effective, biodegradable, durable and eco-friendly construction material that will meet the global needs of thermal rehabilitation. They consist of two or more components with natural fibers in order to obtain specific characteristics such as high tensile, compressive strengths, and reduce shrinkage and cracking. Recent literature works show that it is possible to produce high performance natural fiber composite based in clay matrix, cement and lime or polymer matrix [2-4]. The use of lime or cement lightweight concrete-based natural fibers are more suitable for non-structural parts of the building and promising as one of the possible alternatives to synthetic materials [5]. Concerning natural fibers, some studies highlight that straw bales are excellent construction materials, as well as energy efficient and even fire-resistant. Different investigations have been performed to study the effect of humidity, moisture content and thermal conductivity on straw bales behavior [6,7]. Unfortunately, the majority of studies on straw bales construction is at the straw bale scale and need more accurate laboratory testing in order to understand the behavior at the level of the straw fibers. 
The main purpose of this paper is to characterize the gaseous emissions during the pyrolysis phase of construction material composed of binders (lime or plaster) and cereal straw fibers (wheat or barley) at small scale. This characterization is carried out using flash pyrolysis technique which has been used by several authors to study the thermal degradation of different types of materials [8-10]. These gaseous emissions are investigated on two fiber types and different straw composites. When heated, construction materials represent an important source of pollutant emissions. Besides their thermal performance, the heating of straw composites should lead to low emission of pollutants. Therefore, the proposed composites gaseous emissions characterization will aim to evaluate their contribution to environmental pollution, which is considered one of various problems humanity faces. On the other hand, the investigation of gaseous emissions is necessary to evaluate fire behavior, predict ignition and smoke evolution of these materials for building applications. The present paper is organized as follows: The next section is devoted to the preparation of the straw composites and to the description of pyrolysis flash apparatus; "Results and discussions" provides the gaseous emissions data of straw fibers and straw composite materials; finally, conclusion of this work is presented in "Conclusions".

\section{Materials and methods}

Straw-concrete preparation

The utilization of cereal straw is motivated by its large availability and its porous microstructure offering a good thermal property. It is also natural agricultural residue grown during a half or one-year period. Straw is produced in excess to requirement, so it is cheap and easily accessible. While the seed is processed for different food industries, the biomass left behind tends to be a problem. Traditionally, straw has been used for breeding or burned by farmers because of the storage conditions. Thus, the research program proposes a new solution of original lowcost construction material for the valorization of this lost material. Before preparing the composites, a first investigation is performed on the physical properties of straw. Then, two types of straw were selected and investigated for the composite, wheat and barley fibers. In order to facilitate the molding process, short straw fibers were used. The choice of the binder type is of great importance and complexity. It must answer an easy mixer, a perfect coating of fibers, a correct molding and a final composite with good mechanical and thermal properties. In this case of study, two types of binders were selected and investigated for the composite, lime and plaster.

As mentioned above, the main purpose of this research work is to find an optimal composition (straw-binder) using the lower gaseous emission as criterion for the new strawconcrete material. At this stage of the work, we will present the gaseous emission of the developed straw composite materials. A total of four mixtures were prepared using the water to binder $(W / B)$ mass ratio of 1.1 and two values $(0.2$ and 0.4 ) of the fiber to binder mass ratio $(S / B)$. The mixture was produced using a horizontal mixer of a volume of $35 \mathrm{~L}$. The procedure of the samples preparation was done as Belayachi et al. [11]. In this previous work, it has been demonstrated that these four straw composite materials have low thermal conductivity and good mechanical
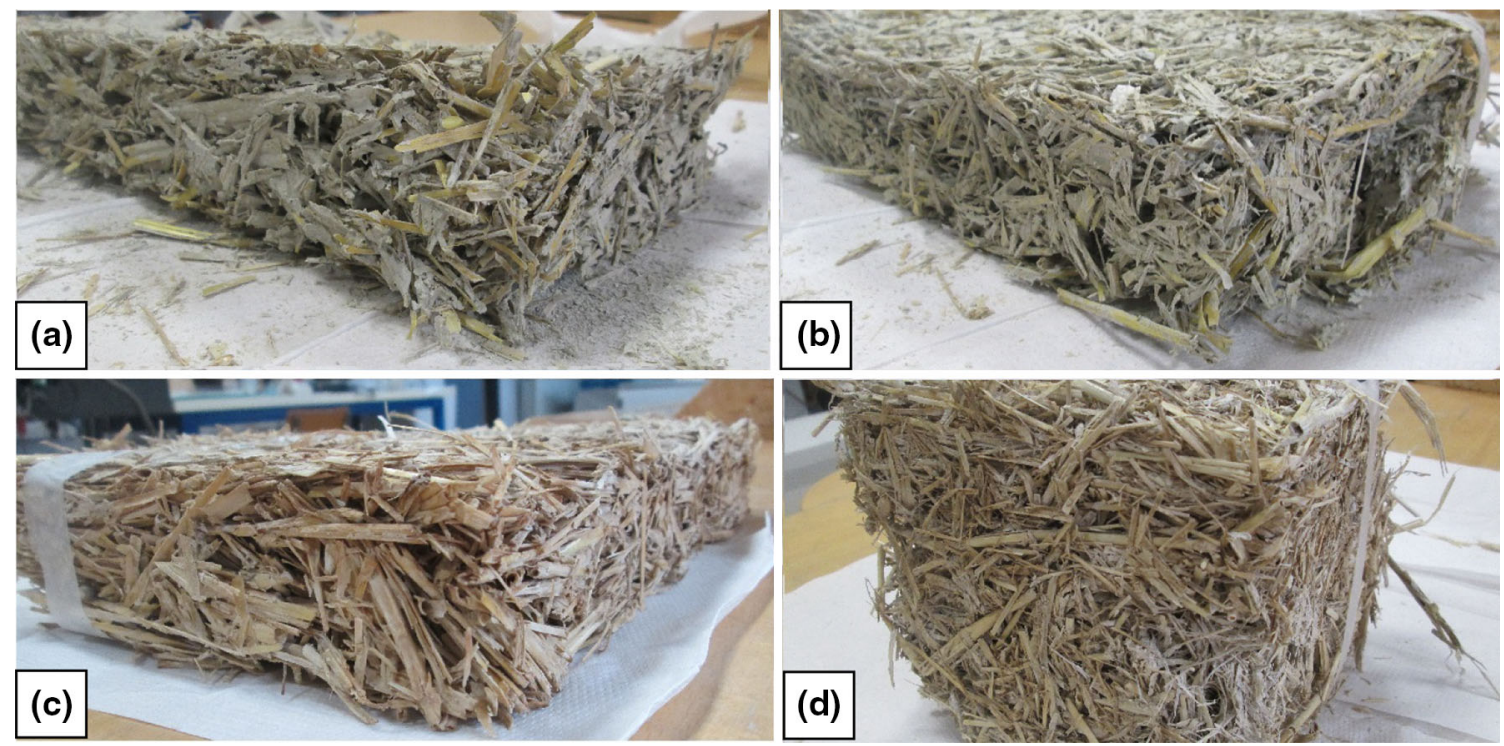

Fig. 1 The lightweight straw-concrete materials: a $F_{2, \mathrm{LW}}$; b $F_{2, \mathrm{LB}} ; \mathbf{c} F_{3, \mathrm{~PB}} ; \mathbf{d} F_{3, \mathrm{PW}}$ 
properties among many mixtures tested. Figure 1 shows the different composite materials which are $F_{2, \mathrm{LW}}$ (wheat/lime with a $S / B$ ratio of 0.2 ), $F_{2, \mathrm{LB}}$ (barley/lime with a $S / B$ ratio of 0.2 ), $F_{3, \mathrm{~PB}}$ (barley/plaster with a $S / B$ ratio of 0.4 ) and $F_{3, \mathrm{PW}}$ (wheat/plaster with a $S / B$ ratio of 0.4 ).

Flash pyrolysis experiments

The identification of pyrolysis gases released by straws, binders and composites has been made using a flash

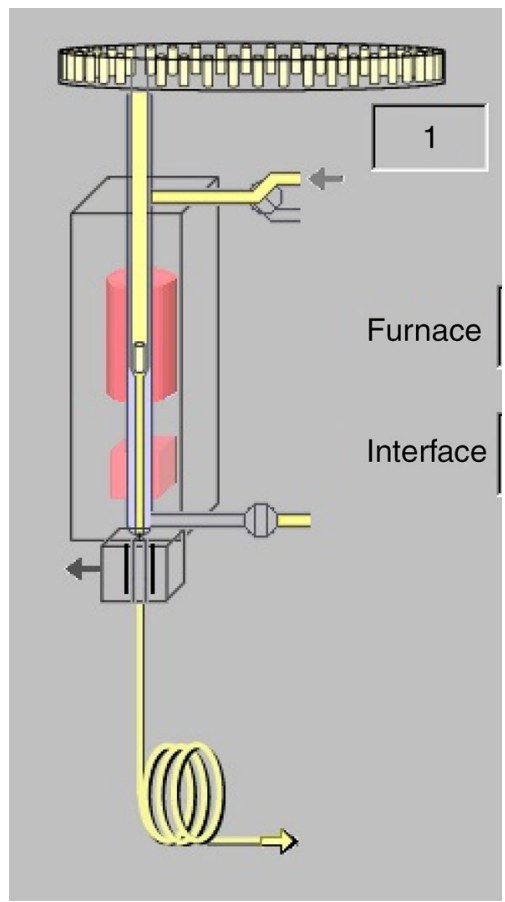

Fig. 2 A schematic overview of the EGA pyrolyser

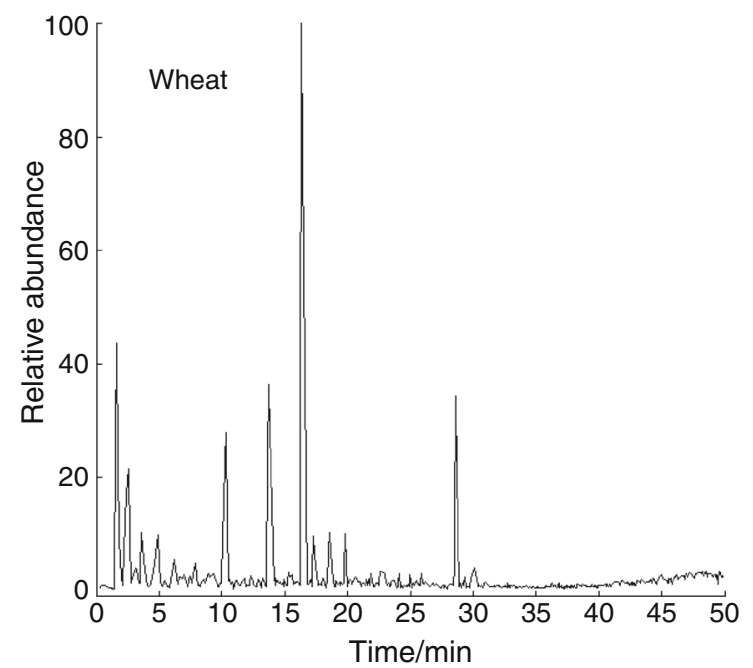

pyrolysis device. The pyrolyser was a Frontier Lab EGA 2020 pyrolyser equipped with an AS-1020E auto-shot sampler coupled with a gas chromatograph and a mass spectrometer (GCMS Shimadzu QP 2010 Ultra). GC separations were done using a SLB-5MS (Supelco) capillary column $(30 \mathrm{~m}$ long, $0.25 \mathrm{~mm}$ i.d, $0.25 \mu \mathrm{m}$ phase thickness). The injector temperature was set to $250{ }^{\circ} \mathrm{C}$. The column temperature was programmed from 50 to $300{ }^{\circ} \mathrm{C} \mathrm{min}{ }^{-1}$ with a rate of $5{ }^{\circ} \mathrm{C} \mathrm{m}^{-1}$ and held at $300{ }^{\circ} \mathrm{C}$ for $9 \mathrm{~min}$. The ionization mode was electron impact $(70 \mathrm{eV})$, and the source temperature was $220^{\circ} \mathrm{C}$. Helium was used as carrier gas with a volume flow rate of $1 \mathrm{~mL} \min ^{-1}$.

This apparatus is widely used to characterize the thermal degradation of various materials [12-14]. To ensure the samples homogenization, straw composites as well as straw fibers are crushed using a laboratory mill. About $2 \mathrm{mg}$ of crushed sample is placed inside an inox cup and put in the sampler. The inox cup falls into the micro-oven isothermally heated at $300{ }^{\circ} \mathrm{C}$. Figure 2 shows a schematic overview of the described experimental setup. The pyrolysis products were identified on the basis of their GC retention times and by comparison of their mass spectra with those of standards and of NIST library. In order to ensure the repeatability, each pyrolysis was performed in duplicates.

\section{Results and discussion}

The gaseous emissions of straw composite materials and of two straw fibers at $300{ }^{\circ} \mathrm{C}$ have been investigated. Wheat and barley straws are mainly composed of lignin and

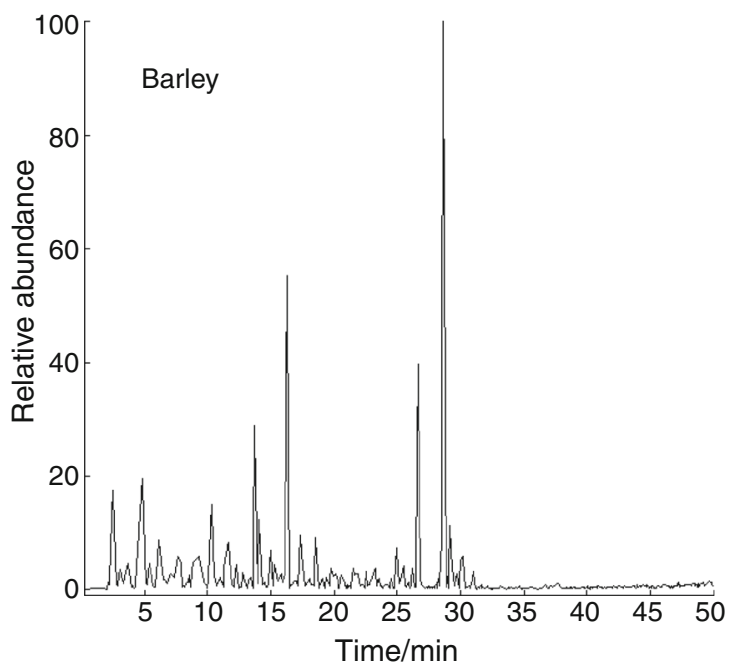

Fig. 3 Total ion current obtained by pyrolysis of wheat and barley straw at $300{ }^{\circ} \mathrm{C}$ 
Table 1 Relative pyrolysis products of straw composite materials heated at $300{ }^{\circ} \mathrm{C}$

\begin{tabular}{|c|c|c|c|c|c|c|c|}
\hline \multirow[t]{2}{*}{ Compounds } & \multirow[t]{2}{*}{ Formula } & \multirow{2}{*}{$\begin{array}{l}\text { Retention } \\
\text { time/min }\end{array}$} & \multirow{2}{*}{$\begin{array}{l}\text { Molecular } \\
\text { mass/g mol }^{-1}\end{array}$} & \multicolumn{4}{|c|}{ Relative emission/\% } \\
\hline & & & & $F_{2, \mathrm{LW}}$ & $F_{2, \mathrm{LB}}$ & $F_{3, \mathrm{~PB}}$ & $F_{3, \mathrm{PW}}$ \\
\hline \multicolumn{8}{|l|}{ Aldehydes } \\
\hline Dodecanal & $\mathrm{C}_{12} \mathrm{H}_{24} \mathrm{O}$ & 19.29 & 184 & 6.13 & 5.27 & 0.41 & 7.92 \\
\hline Octadecanal & $\mathrm{C}_{18} \mathrm{H}_{36} \mathrm{O}$ & 36.08 & 268 & 0.86 & 0.57 & 33.51 & 14.16 \\
\hline Hexadecanal & $\mathrm{C}_{16} \mathrm{H}_{32} \mathrm{O}$ & 29.21 & 240 & 0.82 & 0.58 & 0.16 & 0.21 \\
\hline Tetradecanal & $\mathrm{C}_{14} \mathrm{H}_{28} \mathrm{O}$ & 24.51 & 212 & 2.13 & 1.49 & 0.28 & 0.01 \\
\hline \multicolumn{8}{|l|}{ Ketones } \\
\hline Heptadecanone & $\mathrm{C}_{17} \mathrm{H}_{36}$ & 31.01 & 240 & 7.57 & 3.86 & 0.74 & 0.49 \\
\hline Pentadecanone & $\mathrm{C}_{15} \mathrm{H}_{30} \mathrm{O}$ & 26.52 & 226 & 3.68 & 4.70 & 0.49 & 0.17 \\
\hline Hexadecanone & $\mathrm{C}_{16} \mathrm{H}_{32} \mathrm{O}$ & 28.81 & 240 & 1.33 & 0.53 & 0.08 & 0.06 \\
\hline Pentadecanone trimethyl & $\mathrm{C}_{18} \mathrm{H}_{36} \mathrm{O}$ & 29.72 & 268 & 3.87 & 4.36 & 0.01 & 0.00 \\
\hline \multicolumn{8}{|l|}{ Alkenes } \\
\hline Hexadecene & $\mathrm{C}_{16} \mathrm{H}_{32}$ & 23.97 & 224 & 1.08 & 0.95 & 0.06 & 0.13 \\
\hline Dodecene & $\mathrm{C}_{12} \mathrm{H}_{24}$ & 13.09 & 168 & 4.06 & 3.75 & 0.12 & 0.06 \\
\hline Tetradecene & $\mathrm{C}_{14} \mathrm{H}_{28}$ & 18.78 & 196 & 1.79 & 1.70 & 0.45 & 0.15 \\
\hline Heptadecene & $\mathrm{C}_{17} \mathrm{H}_{34}$ & 27.17 & 238 & 1.50 & 1.42 & 1.76 & 0.84 \\
\hline Octadecene & $\mathrm{C}_{18} \mathrm{H}_{36}$ & 28.65 & 252 & 1.80 & 1.18 & 0.09 & 0.13 \\
\hline \multicolumn{8}{|l|}{ Alcohols } \\
\hline Dodecanol & $\mathrm{C}_{12} \mathrm{H}_{26} \mathrm{O}$ & 21.06 & 186 & 22.25 & 1.93 & 0.13 & 0.04 \\
\hline Tetradecanol & $\mathrm{C}_{14} \mathrm{H}_{30} \mathrm{O}$ & 26.06 & 214 & 4.87 & 9.79 & 0.08 & 0.01 \\
\hline Hexadecanol & $\mathrm{C}_{16} \mathrm{H}_{34} \mathrm{O}$ & 30.60 & 242 & 1.30 & 3.27 & 0.44 & 0.05 \\
\hline \multicolumn{8}{|l|}{ Acids } \\
\hline Hexadecanoic acid methyl ester & $\mathrm{C}_{17} \mathrm{H}_{34} \mathrm{O}_{2}$ & 31.48 & 270 & 4.25 & 7.56 & 4.33 & 0.01 \\
\hline Octadecanoic acid methyl ester & $\mathrm{C}_{19} \mathrm{H}_{34} \mathrm{O}_{2}$ & 35.47 & 298 & 1.70 & 4.94 & 1.16 & 3.79 \\
\hline Hexanedioic acid dioctyl ester & $\mathrm{C}_{22} \mathrm{H}_{42} \mathrm{O}_{4}$ & 40.18 & 370 & 1.74 & 0.28 & 0.33 & 0.09 \\
\hline \multicolumn{8}{|l|}{ Alkanes } \\
\hline Tetradecane & $\mathrm{C}_{14} \mathrm{H}_{30}$ & 19.00 & 198 & 1.66 & 0.67 & 0.31 & 7.93 \\
\hline Heneicosane & $\mathrm{C}_{21} \mathrm{H}_{44}$ & 45.10 & 296 & 0.77 & 3.54 & 0.26 & 2.40 \\
\hline Tetratetracontane & $\mathrm{C}_{44} \mathrm{H}_{90}$ & 47.99 & 618 & 1.91 & 14.09 & 5.74 & 11.56 \\
\hline \multicolumn{8}{|l|}{ Lignin moieties } \\
\hline Benzene dimethoxy methyl & $\mathrm{C}_{9} \mathrm{H}_{12} \mathrm{O}_{2}$ & 15.67 & 152 & 17.58 & 4.42 & 9.40 & 7.37 \\
\hline Methoxy vinylphenol & $\mathrm{C}_{9} \mathrm{H}_{10} \mathrm{O}_{2}$ & 16.74 & 150 & 1.39 & 4.26 & 0.04 & 24.79 \\
\hline Phenol methoxy & $\mathrm{C}_{7} \mathrm{H}_{8} \mathrm{O}_{2}$ & 10.44 & 124 & 0.72 & 4.82 & 1.16 & 3.78 \\
\hline Phenol dimethoxy & $\mathrm{C}_{8} \mathrm{H}_{10} \mathrm{O}_{3}$ & 17.72 & 154 & 3.12 & 10.05 & 37.72 & 13.76 \\
\hline Phenol methoxy propenyl & $\mathrm{C}_{10} \mathrm{H}_{12} \mathrm{O}_{2}$ & 18.18 & 164 & 0.12 & 0.05 & 0.73 & 0.11 \\
\hline
\end{tabular}

cellulose as can be seen regarding their pyrolysis products. Indeed, acetic acid and furan methanol were produced from cellulose degradation, whereas aromatic compounds such as methoxy phenol, vinylphenol, methoxy vinyl phenol and vanillin originate from lignin. The relative percentage of each compound is calculated as the ratio between its area and the sum of all the identified compounds area. The pyrolysis of the two straws leads to the same compounds but differs by their relative percentages. Methoxy vinyl phenol is the major product from wheat, whereas trimethyl pentadecanone which originate from chlorophyll is the major compound released by pyrolysis of barley (Fig. 3). The same behavior has been observed in the literature for pyrolysis products analysis of several types of vegetation $[15,16]$.

The pyrolysis of the composite materials was performed at the same temperature for comparison. The pyrolysis products of the four straw/binder materials are presented in Table 1. A total of 27 compounds have been identified in each composite material. These compounds can be grouped into seven chemical families which are aldehydes, ketones, alkene, alcohols, acids, alkanes and lignin moieties. For the $S / B$ ratio of 0.2 , the major pyrolysis product of $F_{2, \mathrm{LW}}$ at $300{ }^{\circ} \mathrm{C}$ is dodecanol $\left(\mathrm{C}_{12} \mathrm{H}_{26} \mathrm{O}\right)$. Relating to $S / B$ ratio of 

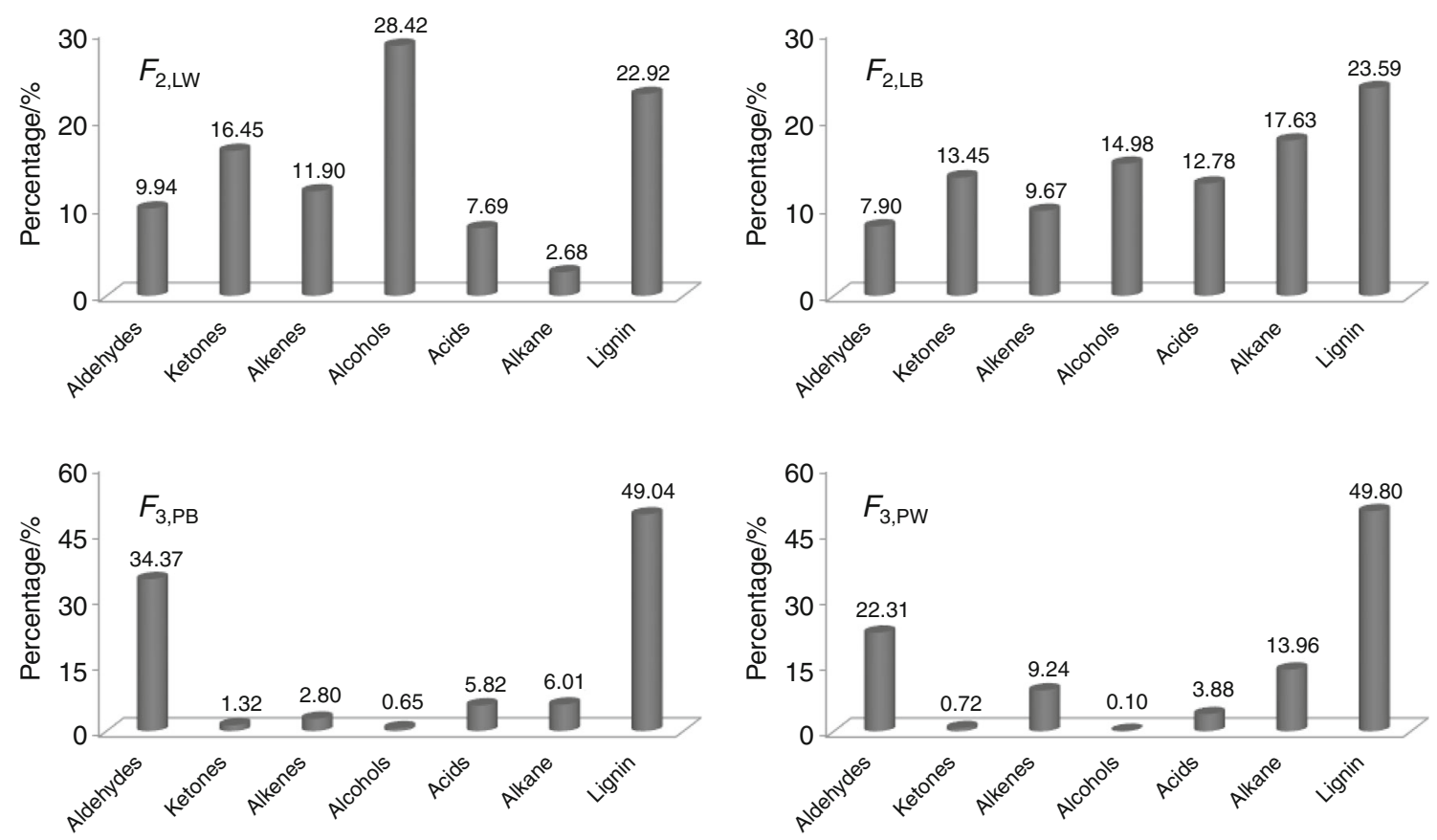

Fig. 4 Percentages of the different class of compounds in composite materials heated at $300{ }^{\circ} \mathrm{C}$

0.4 , the major $F_{3, \mathrm{~PB}}$ pyrolysis product (38\%) is phenol dimethoxy $\left(\mathrm{C}_{8} \mathrm{H}_{10} \mathrm{O}_{3}\right)$, whereas methoxy vinylphenol $\left(\mathrm{C}_{9} \mathrm{H}_{10} \mathrm{O}_{2}\right)$ is the major pyrolysis product from $F_{3, \mathrm{PW}}(25 \%)$. Figure 4 illustrates the relative percentage of each family released by the pyrolysis of the different composite materials. Lignin moieties are the main class of compounds produced by all composite material. However, Straw/plaster composite materials mainly produce aldehydes and lignin moieties, whereas in the case of straw/lime composite materials, the products restarted in several class of compounds. The relative percentage of aldehydes for $F_{3, \mathrm{Pw}}$ is 2.25 more significant than for $F_{2, \mathrm{LW}}$. Ketones and alcohols are relatively more represented in straw/lime than in straw/plaster composites. The relative percentage of ketones is 23 and 10 times higher for $F_{2, \mathrm{LW}}$ and $F_{2, \mathrm{LB}}$ than for $F_{3 \text {,PW }}$ and $F_{3, \mathrm{~PB}}$ respectively. The relative percentage of alcohols for $F_{2, \mathrm{LW}}$ and $F_{2, \mathrm{LB}}$ are 286 and 23 times higher than for $F_{3, \mathrm{PW}}$ and $F_{3, \mathrm{~PB}}$ respectively. Except for $F_{3, \mathrm{~PB}}$, the relative percentage of alkenes are in the same order of magnitude for the straw/binder composites (9-12\%). The highest acids and alkanes relative percentages are found in $F_{2, \mathrm{LB}}$ composite, whereas the lowest ones are obtained in $F_{2, \mathrm{LW}}$ and $F_{3, \mathrm{PW}}$.

\section{Conclusions}

Straw fibers (wheat and barley) have been mixed with mineral binders (lime and plaster) to develop new composite materials destined to the thermal insulation in buildings. The gaseous emissions of basic constituents and straw composite materials were studied thanks to Py-GC/ MS at the selected temperature of $300{ }^{\circ} \mathrm{C}$. This device allows the analyses of the pyrolysis products in the complex matrix where 27 compounds have been found for composite materials, shared in seven. Contrarily to straws which produced mainly lignin cellulosic moieties, we observed significant differences between the different composite samples. The fiber variety and the $S / B$ ratio seem to play an important role on the pyrolysis products composition of the straw composites. In a future work, we plan to investigate the gaseous emissions of this kind of materials varying the $W / B$ (water/binder) and $S / B$ (straw/binder) ratios with better thermal insulating performance for building at numerous heated temperatures. The classification of the different prepared samples according to their toxicity and fire risk will be also studied. This will permit to suggest new insulation materials destined to construction field with low environmental and human life risks.

\section{References}

1. Huang X, Netravali A. Characterization of flax fiber reinforced soy protein resin based green composites modified with nano-clay particles. Compos Sci Technol. 2007;67:2005-14.

2. Millogo Y, Morel JC, Aubert JE, Ghavami K. Experimental analysis of pressed Adobe Blocks reinforced with Hibiscus cannabinus fibers. Constr Build Mater. 2014;52:71-8.

3. Ali M, Chouw N. Experimental investigations on coconut-fibre rope tensils strength and pullout from coconut fibre reinforced concrete. Constr Build Mater. 2013;41:681-90. 
4. Ramli M, Kwan WH, Abas NF. Strength and durability of coconut-fiber-reinforced concrete in aggressive environments. Constr Build Mater. 2013;38:554-66.

5. Pacheco-Torgal F. Eco-efficient construction and building materials research under the EU framework programme horizon 2020. Constr Build Mater. 2014;51:151-62.

6. Ashour T, Wieland H, Georg H, Bockisch FJ, Wu W. The influence of natural reinforcement fibers on insulation values of earth plaster for straw bale buildings. Mater Design. 2010;31:4676-85.

7. Ashour T, Goerg H, Wu W. An experimental investigation on equilibrium moisture content of earth plaster with natural reinforcement fibers for straw bale buildings. Appl Therm Eng. 2011;31:293-303.

8. Santos MR, Sales RF, Silva AOS, Teixeira CM, Pacheco JGA, Fréty R. Flash pyrolysis of myristic acid adsorbed on supported nickel catalysts for biofuel production. J Therm Anal Calorim. 2015; doi:10.1007/s10973-014-4375-1.

9. Zhang H, Zhao H, Zheng K, Li X, Liu G, Wang Y. Diminishing hazardous air pollutant emissions from pyrolysis of furan no-bake binders using methanesulfonic acid as the binder catalyst. J Therm Anal Calorim. 2014;116:373-81.
10. Sezer M, Bilgesü AY, Karaduman A. Flash pyrolysis of Silopiasphaltite in a free-fall reactor under vacuum. J Anal Appl Pyrol. 2008;82:89-95.

11. Belayachi N, Bouasker M, Hoxha D, Al-Mukhtar M. Thermomechanical behaviour of an innovant straw lime composite for thermal insulation applications. Appl Mech Mater. 2013;390: $542-6$.

12. Lou R, Wu SB, Lv GJ. Effect of conditions on fast pyrolysis of bamboo lignin. J Anal Appl Pyrol. 2010;89:191-6.

13. Ngo PT, Rumpel C, Dignac MF, Billou D, Duc TT, Jouquet P. Ecol Eng. 2011;37:269-276

14. Bradley A Organic geochemical biosignatures in alkaline hydrothermal ecosystems. Ph.D. Thesis, Massachusetts Institute of Technology 2008:269.

15. Ross K, Mazza G. Comparative analysis of pyrolysis products from a variety of herbaceous canadian crop residues. World J Agr Sci. 2011;7:763-76.

16. Heigenmoser A, Liebner F, Windeisen E, Richter K. Investigation of thermally treated beech (Fagussylvatica) and spruce (Piceaabies) by means of multifunctional analytical pyrolysisGC/MS. J Anal Appl Pyrol. 2013;100:117-26. 